\title{
Differential microRNA expression and identification of putative miRNA targets and pathways in head and neck cancers
}

\author{
NURUL-SYAKIMA AB MUTALIB ${ }^{1}$, CHEAH YOKE-KQUEEN ${ }^{1,2}$, SABARIAH ABDUL RAHMAN $^{2,3}$, \\ SHIRAN MOHD SIDIK ${ }^{3}$, AVATAR SINGH MOHAN SINGH ${ }^{4}$ and LEE LEARN-HAN ${ }^{1}$ \\ ${ }^{1}$ Department of Biomedical Science, Faculty of Medicine and Health Sciences, ${ }^{2}$ UPM-MAKNA Cancer Research Laboratory, \\ Institute of Bioscience, ${ }^{3}$ Department of Pathology, Faculty of Medicine and Health Sciences, University Putra Malaysia, \\ 43400 UPM Serdang, Selangor Darul Ehsan; ${ }^{4}$ Department of Otorhinolaryngology, \\ Taiping General Hospital, Jalan Taming Sari, 34000 Taiping, Perak, Malaysia
}

Received March 10, 2011; Accepted April 26, 2011

DOI: $10.3892 /$ ijmm.2011.714

\begin{abstract}
MicroRNAs (miRNAs) are small noncoding RNAs that involved in various cancer-related cellular processes. Diverse studies on expression profiling of miRNAs have been performed and the data showed that some miRNAs are up-regulated or down-regulated in cancer. Until now, there are no data published on the miRNA expression in head and neck cancers from Malaysia. Hence, this study aimed to investigate potentially crucial miRNAs in head and neck cancer patients from Malaysian populations. A global miRNA profiling was performed on 12 samples of head and neck cancer tissue using microarray analysis followed by validation using real-time RT-PCR. Microarray analysis identified 10 miRNAs that could distinguish malignant head and neck cancer lesions from normal tissues; 7 miRNAs (hsa-miR-181a-2*, hsa-miR-29b-1*, hsa-miR-181a, hsa-miR-181b, hsa-miR-744, hsa-miR-1271 and hsa-miR-221*) were up-regulated while 3 miRNAs (hsa-miR141, hsa-miR-95 and hsa-miR-101) were down-regulated. These miRNAs may contribute in a simple profiling strategy to identify individuals at higher risk of developing head and neck cancers, thus helping in the elucidation of the molecular mechanisms involved in head and neck cancer pathogenesis.
\end{abstract}

\section{Introduction}

Head and neck cancers include cancers that originate from the nasopharynx, oral cavity, lips, nose and paranasal sinus, larynx,

Correspondence to: Dr Cheah Yoke-Kqueen, Department of Biomedical Science, Faculty of Medicine and Health Sciences, and UPM-MAKNA Cancer Research Laboratory, Institute of Bioscience, University Putra Malaysia, 43400 UPM Serdang, Selangor Darul Ehsan, Malaysia

E-mail: ykcheah@medic.upm.edu.my

Key words: microRNA, head and neck cancers, microarray, quantitative reverse transcription-PCR, in silico analysis oropharynx, hypopharynx, thyroid and the salivary glands. In 2006, 2884 cases of head and neck cancers were reported in Peninsular Malaysia with nasopharyngeal cancer ranked first constituting $34 \%$ of the cases. Malaysia is a multiracial country that consist of three major ethnicities; Malay, Chinese and Indian. Distribution of head and neck cancers are varied according to ethnicity; laryngeal, oral and pharyngeal cancers are more common in Indians, followed by Malay and Chinese. On the other hand, nasopharyngeal cancer is most common among the Chinese followed by the Malays, the indigenous East Malaysians and Indians.

The worldwide five-year relative survival rate for head and neck cancers is generally $<50 \%$ and has remained unchanged for more than 30 years (1). Furthermore, the survival rate for patients diagnosed with regional or distant disease (with spread to nearby or distant organs and lymph nodes) was even lower (2). One of the factors that contribute to this poor survival rate is the late-stage diagnosis (1). Due to this fact, a molecular approach that enables the early stage detection of these cancers may be very helpful in improving prognosis.

MicroRNAs (miRNA) are endogenous, small, noncoding RNAs of 17-25 nucleotides that are thought to regulate almost $30 \%$ of human genes $(3,4)$. The first miRNA discovery was in Caenorhabditis elegans and later studies elucidated that miRNAs are also widely conserved in animals and plants (4-6). Its crucial involvement in various cancer-related cellular processes, such as cell differentiation, cell division (7), apoptosis (8) and cell cycle regulation (9) have made it important to investigate the role of this molecule in head and neck cancers especially in a multiracial country like Malaysia.

Microarray is a global expression analysis that permits interrogation of the expression of thousands of genes simultaneously in a high-throughput manner, offering precious information on disease pathology and progression, thus leading to an improved diagnostic approach for cancer (10). This analysis method has been widely used for miRNA expression profiling and altered miRNA expression in head and neck cancer has been investigated by several groups (11) internationally but none has been conducted in Malaysia. Thus this study is the first to provide information about differences in 
Table I. Demographics and clinical characteristics of patients with head and neck cancer.

\begin{tabular}{|c|c|}
\hline Characteristics & No. \\
\hline \multicolumn{2}{|l|}{ Gender } \\
\hline Man & 6 \\
\hline Woman & 3 \\
\hline \multicolumn{2}{|l|}{ Age } \\
\hline Year, median (range) & $60(20-83$-year old $)$ \\
\hline \multicolumn{2}{|l|}{ Race } \\
\hline Malay & 5 \\
\hline Chinese & 2 \\
\hline Indian & 2 \\
\hline \multicolumn{2}{|l|}{ TNM staging } \\
\hline $\mathrm{T} 1$ & 0 \\
\hline $\mathrm{T} 2$ & 2 \\
\hline $\mathrm{T} 3$ & 2 \\
\hline $\mathrm{T} 4$ & 5 \\
\hline \multicolumn{2}{|c|}{ Pathological lymph node status } \\
\hline N0 & 3 \\
\hline $\mathrm{N}^{+}$ & 6 \\
\hline \multicolumn{2}{|l|}{ Anatomical site } \\
\hline Buccal & 2 \\
\hline Supraglottic & 2 \\
\hline Nasopharynx & 2 \\
\hline Retromolar & 1 \\
\hline External ear & 1 \\
\hline Nasal cavity & 1 \\
\hline
\end{tabular}

TNM, tumor node metastasis.

miRNA expression signatures between head and neck cancer and normal tissues among Malaysians.

\section{Materials and methods}

Sample collection. This study was comprised of 9 head and neck cancer patients that underwent surgical resection at Taiping General Hospital, Perak, Malaysia. All diagnoses were histologically verified by the pathologists. Ethics approvals were obtained from the local research Ethics Committees (National Institutes of Health and Medical Research Ethics Committee, Faculty of Medicine and Health Sciences, University Putra Malaysia, Malaysia). All patients gave written informed consent. The tissues were cut $<0.5 \mathrm{~cm}$ in at least one dimension and the specimens were submerged in five volumes of RNAlater (Ambion, Austin, TX, USA) at room temperature for $2 \mathrm{~h}$ (to allow the solution to thoroughly penetrate the tissue) and kept at $-80^{\circ} \mathrm{C}$ until they were subjected to total-RNA extraction. RNAlater is an aqueous, non-toxic tissue storage reagent that rapidly permeates tissues to stabilize and protect cellular RNA. This solution eliminates the need to instantly process tissue samples or to freeze samples in liquid nitrogen for later processing.
Table II. Designation of the total-RNA samples.

\begin{tabular}{lc}
\hline Samples & Type \\
\hline RL1 & Cancer \\
RL3 & Cancer \\
RL7 & Cancer \\
RL8 & Cancer \\
RL9 & Cancer \\
RL19 & Cancer \\
RL17Ca & Cancer \\
RL25Ca & Cancer \\
RL29Ca & Cancer \\
RL17N & Normal \\
RL25N & Normal \\
RL29N & Normal \\
\hline
\end{tabular}

There were 12 samples of total-RNA from 9 patients; 9 cancer tissues and 3 normal tissues. RL17, RL25 and RL29 are paired tissues (cancer and normal), whereas only cancer tissues are available for the rest.

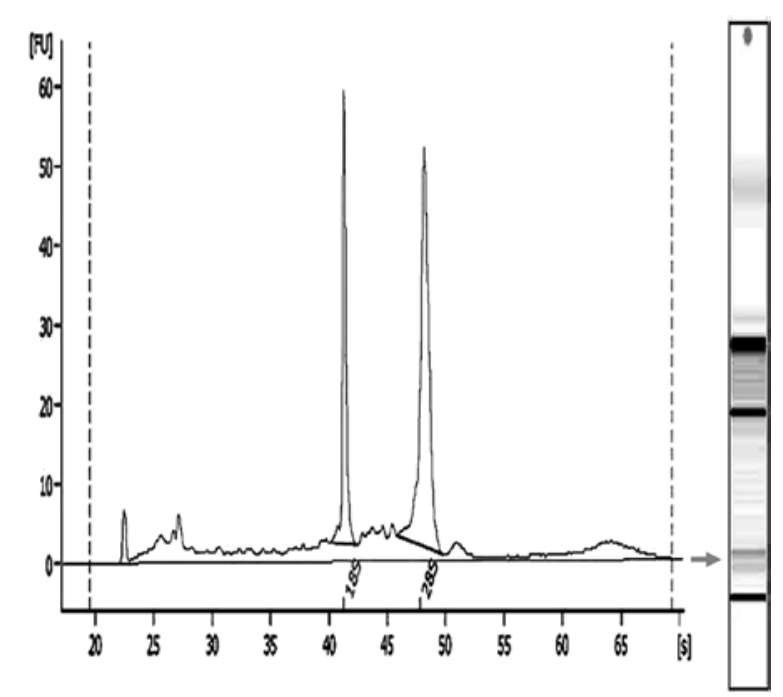

Figure 1. Electropherogram obtained from bioanalyzer analysis of total-RNA extracted from head and neck tissue. The arrow represents the presence of small RNA species including miRNAs. Highly intact RNA ( RIN $\geq 7)$ is indicated by sharp peaks of $18 \mathrm{~S}$ and $28 \mathrm{~S}$.

Histologically-verified cancer and paired normal tissues were obtained from 3 patients ( 2 females and 1 male; 63, 59 and 46-year old, respectively) while for the rest only cancerous tissues were available. Normal tissues were $>2 \mathrm{~cm}$ away from the tumor. Full patient demographics are provided in Table I and the designation of the total-RNA samples is summarized in Table II.

Total-RNA extraction. Total-RNA was extracted using the Total-RNA Purification kit (Norgen Biotek, Canada). Prior to extraction, sterile, RNase-free screw-cap $2 \mathrm{ml}$ tubes were filled with $700 \mathrm{mg}$ of $0.1 \mathrm{~mm}$ glass beads (Biospec Products, Bartlesville, OK). Then $600 \mu \mathrm{l}$ of lysis solution and $6 \mu \mathrm{l}$ of $\beta$-mercaptoethanol were added to each tube. Tissue $(10 \mathrm{mg})$ 
Table III. Differentially expressed miRNAs in head and neck cancer samples compared to normal samples.

\begin{tabular}{|c|c|c|c|c|}
\hline miRNA & $\begin{array}{c}\text { Unpaired t-test } \\
\text { P-value }\end{array}$ & $\begin{array}{c}\text { Fold-change } \\
\log 2(\text { cancer/normal })\end{array}$ & $\begin{array}{c}\text { Cancer vs. } \\
\text { normal }\end{array}$ & Chromosomal location \\
\hline hsa-miR-29b- $1^{*}$ & 0.00315 & 1.18 & up-regulated & $7: 130212758-130212838(-)$ \\
\hline hsa-miR-181a-2* & 0.000613 & 1.11 & up-regulated & $9: 126494542-126494651(+)$ \\
\hline hsa-miR-221* & 0.0273 & 0.80 & up-regulated & $X: 45490529-45490638(-)$ \\
\hline hsa-miR-1271 & 0.0439 & 0.65 & up-regulated & $5: 175794949-175795034(+)$ \\
\hline hsa-miR-744 & 0.00264 & 0.61 & up-regulated & 17:11925941-11926038(+) \\
\hline hsa-miR-181b & 0.0163 & 0.60 & up-regulated & $1: 197094625-197094734(-)$ \\
\hline hsa-miR-181a & 0.0321 & 0.43 & up-regulated & 1:197094796-197094905 (-) \\
\hline hsa-miR-141 & 0.00181 & -0.46 & down-regulated & $12: 6943521-6943615(+)$ \\
\hline hsa-miR-95 & 0.00577 & -0.46 & down-regulated & 4:8057928-8058008 (-) \\
\hline hsa-miR-101 & 0.0202 & -0.51 & down-regulated & $1: 65296705-65296779(-)$ \\
\hline
\end{tabular}

was placed into the tube and subjected to lysis using a Biospec mini-bead beater (BioSpec Products) at the maximum speed until the tissue became small fragments $(40-80 \mathrm{sec}$, at $20 \mathrm{sec}$ intervals). Subsequent RNA extraction steps followed the manufacturer's instruction. The absorbance at 260/280 $\mathrm{nm}$ and concentration of the RNA were determined by using the Biophotometer 6131 (Eppendorf, USA) and the RNA integrity was confirmed with the Agilent 2100 Bioanalyzer (Agilent Technologies, Santa Clara, CA, USA). The RNA integrity number (RIN) was calculated for every case. Total-RNA of 12 samples were chosen for microarray based on the RIN number $(\geq 7)$ and an example of electropherogram is shown in Fig. 1.

miRNA microarray. miRNA microarray was performed using the Human v2 MicroRNA Expression Profiling kit (Illumina, San Diego, CA) on BeadChip. All RNA samples were first normalized to approximately $90 \mathrm{ng} / \mu \mathrm{l}$. For each sample, $5 \mu \mathrm{l}$ of normalized RNA was used for the array. All reactions were performed in duplicate. The BeadArray Reader was used to measure the fluorescence intensity. Images were imported into Illumina GenomeStudio and data were analyzed using Illumina's GenomeStudio Gene Expression Module.

The signal values of spike controls were averaged and used as a cut-off value, and sample with signal intensity below the cut-off value were excluded, followed by quantile normalization of the signals intensity on cancer tissues and normal tissues. The signal values were averaged from both replicates. Signals significantly detected were defined as those with a detection $\mathrm{P}<0.01$. After filtration with detection $\mathrm{P}$-value, 493 miRNAs were found to be accurately detected from the array and were further analyzed in Excel 2007 (Microsoft, Seattle, WA). Microsoft Excel has been widely used in micro-array statistical analysis including in miRNA microarray (12-15). The unpaired t-test (t-test with unequal variance) was performed between cancer and normal sample groups and the P-values were calculated. Differentially expressed miRNAs were those with $\mathrm{P}<0.05$. The signal ratio or the expression ratio was logarithmically transformed to the base 2 to obtain the foldchange ( $>0$, up-regulated; $<0$, down-regulated) and the significance was calculated by using $-\log 10$ of the P-value obtained from the unpaired t-tests (16). A heat map was generated for the differentially expressed miRNAs. All of the microarray data presented in this study are in accordance with the Minimum Information about a Microarray Experiment (MIAME) guidelines.

Validation of miRNA microarray data by quantitative RT-PCR ( $q R T-P C R)$. Six miRNAs were chosen for validation (hsamiR-221*, hsa-miR-744, hsa-miR-181b, hsa-miR-181a, hsa-miR-141 and hsa-miR-95) and qRT-PCR was performed using the NCode ${ }^{\mathrm{TM}}$ EXPRESS SYBR ${ }^{\circledR}-$ GreenER $^{\mathrm{TM}}$ miRNA qRT-PCR kit Universal (Invitrogen, Carlsbad, CA, USA). Total-RNA input without additional enrichment was used to conserve precious samples. RNU-48 was used as normalization control or reference gene. Total-RNA $(1 \mu \mathrm{g})$ was subjected to a reverse transcription reaction according to the manufacturer's protocol.

For miRNA qPCR, the Universal qPCR Primer provided in the kit was used as the reverse primer. The forward qPCR primer was specific for the miRNA sequence of interest and was obtained from the NCode ${ }^{\mathrm{TM}}$ miRNA database (http:// escience.invitrogen.com/ncode). However, in some miRNAs, qPCR using primers mentioned above were unsuccessful, thus miRNA-specific primer pairs were designed using PrimerBLAST (http://www.ncbi.nlm.nih.gov/tools/primer-blast). Primer-BLAST was developed at NCBI to help users design specific primers to the input PCR template. It utilizes Primer3 to design PCR primers followed by submission to BLAST search and then automatically analyzed to avoid primer pairs that can cause unspecific amplification of targets.

The qPCR reaction was run in triplicate using the Rotorgene 6000 (Qiagen, Valencia, CA, USA) in a $20 \mu \mathrm{l}$ volume according to manufacturer's protocol with adjustment of annealing time to $15 \mathrm{sec}$. The qRT-PCR amplification products were subsequently analyzed by melting curve analysis and confirmed by $1.8 \%$ agarose gel electrophoresis. A negative control without cDNA template was included to assess the specificity of the qPCR reaction. The fold-change of the miRNAs expression was calculated using the $2^{-\Delta \Delta C t}$ method (17).

Prediction of putative miRNA targets and pathways through in silico analysis. Targets of miRNA differentially expressed 


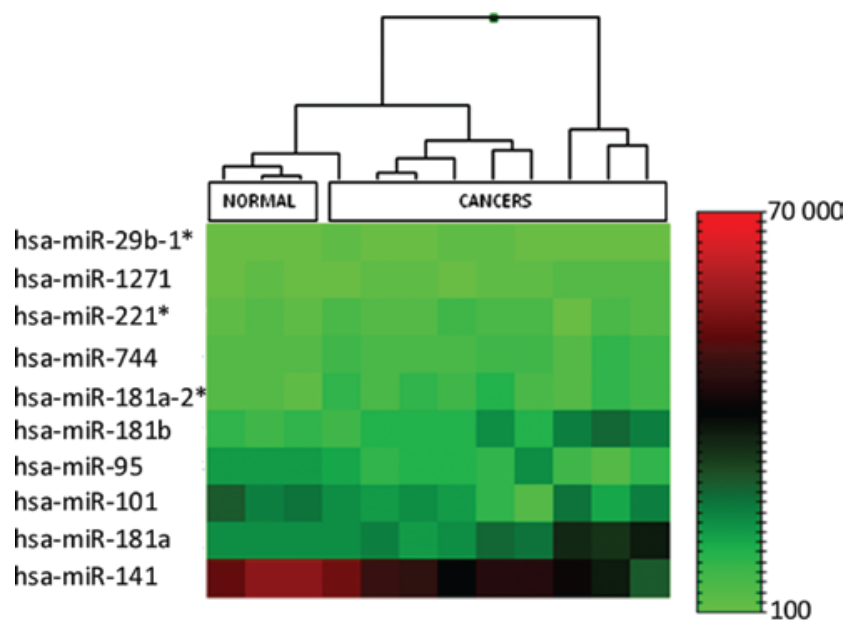

Figure 2. Microarray heat map showing the statistically significant $(\mathrm{P}<0.05)$ differentially expressed miRNAs and the hierarchical clustering of the samples. The analyzed samples are in columns and the miRNAs are presented in rows. The sample-clustering tree appears at the top. The color scale shown represents the relative expression level of a miRNA; red illustrates a high expression level and green illustrates a low expression level.

in head and neck cancers were determined using the DIANAmicroT version 4.0 (freely available at http://diana.cslab.ece. ntua.gr/microT_v4). On the other hand, for identification of putative pathways targeted by miRNAs of interest, the DIANAmiRPath (http://microrna.gr/mirpath) was utilized. Both in silico tools mentioned above were connected to the KEGG (Kyoto Encyclopedia of Genes and Genomes), a database used for representation and analysis of molecular networks involving diseases and drugs (18).

\section{Results}

Microarray analysis was performed to determine the miRNA expression profile in head and neck cancers. When the expression of miRNAs was compared between the normal head and neck samples and malignant samples, 10 miRNAs were found to be aberrantly expressed as summarized in Table III. Among the 10 miRNAs, 7 were up-regulated and 3 were down-regulated in cancer samples compared to normal samples.

A representative heat map of the statistically significant $(\mathrm{P}<0.05)$ results is shown in Fig. 2. The hierarchical clustering based on an Euclidean algorithm generated a tree with a clear distinction of samples in two main groups, represented by normal tissues and cancer tissues. The Volcano plot in Fig. 3 displays the relationship between the significance of miRNAs detected and the fold-change between normal and cancer tissues.

In order to confirm the results obtained from the miRNA microarray, the expression of 6 miRNAs was analyzed by qRT-PCR in the same samples analyzed by the microarray. The fold change of the expression of miRNAs was calculated according to Livak and Schmittgen (19). Results of the qRT-PCR are consistent with those of the microarray analysis. miRNA hsa-miR-221*, hsa-miR-744, hsa-miR-181b and hsa-miR-181a were up-regulated while hsa-miR-141 and hsa-miR-95 were down-regulated (Fig. 4). These results validate the results obtained by the microarray analysis.

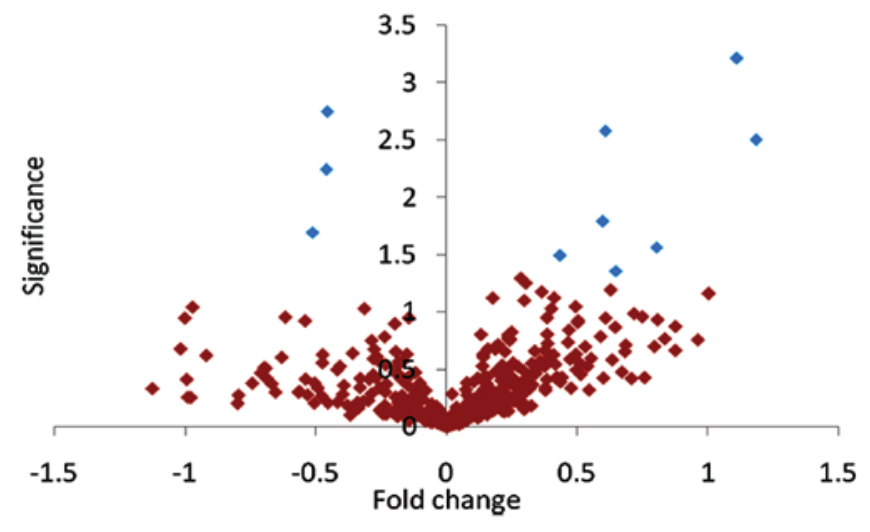

Figure 3. A Volcano plot representing the significance of miRNAs vs. the fold-change. Teh blue color diamonds represent miRNAs which are differentially expressed with $\mathrm{P}<0.05$. Teh up-regulated miRNAs are signified by a positive fold-change value and vice versa.

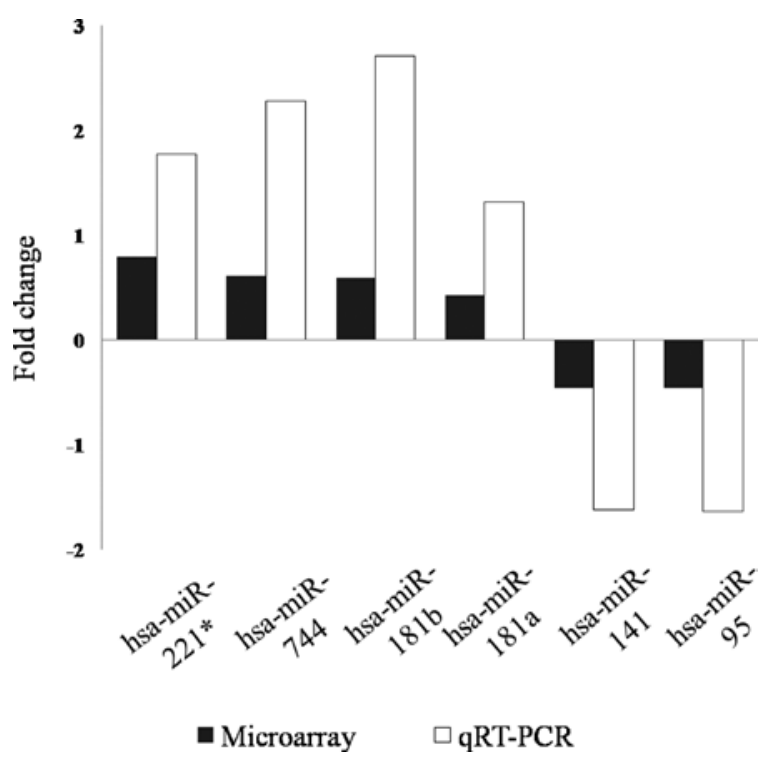

Figure 4. Validation of miRNA microarray results by qRT-PCR in the head and neck cancer samples. The black bars represent values from microarray analysis, whereas the white bars represent qRT-PCR data.

In silico analysis of dysregulated miRNAs in head and neck cancers. Using the medium or the strict Score Threshold setting in the DIANA-microT, genes targeted by particular miRNAs were revealed along with the KEGG pathway enrichment in the target genes. Results obtained through the DIANA-microT version 4.0 are summarized in Table IV. Only the results associated with cancer-related KEGG pathways are displayed.

Using the DIANA mirPath, the list of pathways was narrowed to choose only the pathways that are involved in human cancers according to the KEGG pathway database (http://www.genome. jp/kegg-bin/show_pathway?hsa05200+1956) (Table V).

\section{Discussion}

miRNAs differentially expressed in carcinoma and normal tissues of the head and neck. In recent years, there have been a number of studies that have profiled the miRNA expression 
in various cancers and these differential expressions may be applied to distinguishing tumors and normal tissues (20-30). Moreover, some miRNAs have even been identified as cancer markers or prognostic markers for cancer patients (21,26,30-32). However, data on a miRNA signature of head and neck cancers in Malaysians have not been reported. Hence, the aim of this study was to assess the profiles of miRNA in Malaysian patients diagnosed with head and neck cancers.

miRNAs are differentially expressed between normal and cancerous tissues in agreement with this study. A miRNA expression array was used to determine the miRNA profiles in head and neck cancer tissues and the results showed that the miRNA expression profile can definitely distinguish head and neck cancer tissues from normal tissues. Comparison of the expression of miRNAs resulted in 10 differentially expressed miRNAs; 7 were up-regulated and 3 were down-regulated. The most interesting finding was that, the number of up-regulated miRNAs in carcinoma samples was higher than the number of down-regulated miRNAs. This finding is in agreement with previously published miRNA profiling studies, most of which showed a higher degree of up-regulation than down-regulation of miRNAs in cancer $(33,34)$. Defects in the miRNA processing machinery components could explain the overall increased expression of miRNAs $(35,36)$.

The clustering analysis performed on all the samples based on miRNA expression produced a clustering tree that successfully separated normal from cancer samples. However we did not obtain any differentially expressed miRNAs associated with different stages of head and neck cancers. This could be due to the fact that samples in this study were mostly of advanced stages (stage IV) and there was no sample of stage I. Furthermore, the small size of our sample could represent a limit for the statistical analysis.

Owing to the tissue specificity of miRNAs (37-39), different miRNAs are up-regulated or down-regulated in different types of cancer. Among the interesting findings obtained from this study are the up-regulation of miRNAs of the miR-181 family; hsa-miR-181a-2*, hsa-miR-181a and hsa-miR-181b. Considered as oncogenic, the miR-181 family has also been found to be up-regulated in carcinomas of the ovary (22) and breast (40). Other miRNA studies in head and neck cancers also revealed the up-regulation of the miR-181 family $(34,41,42)$. Using the mouse as an animal model, Wang et al also demonstrated the oncogenic property of this miRNA family (43). On the contrary, hsa-miR-181a and hsa-miR-181b were found to be significantly down-regulated and to function as tumor suppressors in glioma (44). These remarkable discoveries underscore the fact that the same miRNA can act differently among various cancer types; it is thus important to study its function in head and neck carcinogenesis. So far no in-depth study has been conducted to determine the functionality of hsa-miR-181a-2* An extended study of this miRNA family is warranted to investigate its role in head and neck cancers. In this study, the miR-181 family could be considered as an oncomiR (a miRNA that acts as an oncogene) due to its up-regulation in carcinoma tissues. However, functional studies must be performed to validate its cancer-related properties in head and neck cancers.

The down-regulation of hsa-miR-95 in carcinoma tissues observed in this study is in agreement with a similar study by Kozaki et al (41). In addition, hsa-miR-95 was also found to be down-regulated in lung cancer tissues vs. noncancerous lung tissues (21). This finding signifies that hsa-miR-95 could be a tumor suppressor miRNA that leads to carcinoma of the head and neck as well as to lung cancer when its expression is low. On the other hand, Cheng et al discovered that inhibition of hsa-miR-95 in HeLa cells resulted in decreased cell growth (45). This contrast finding supports the notion that hsa-miR-95 is an oncomiR in that cervical cancer cell line.

New miRNAs differentially expressed in head and neck cancers. Some of the differentially expressed miRNAs identified in this study have not been reported to be differentially expressed in other similar studies pertaining to head and neck cancers. Noteworthy is the expression level of hsa-miR-744, which is significantly up-regulated, signifying that it could be a miRNA signature specific for head and neck cancers. However, since samples used in this study were mostly of advanced stage tumors, perhaps hsa-miR-744 is the late diagnosis marker of head and neck cancers. This notion may similarly be applied to hsa-miR-141 and hsa-miR-101, which are significantly down-regulated. Even though no miRNA studies of head and neck cancers have identified hsa-miR-141, this miRNA has been found to be down-regulated in other cancers, such as gastric and renal cell carcinoma $(46,47)$. Meanwhile hsa-miR101 is one of the best studied miRNA in cancer, and its down-regulation has been reported in ovarian (22) and hepatocellular cancer (48). hsa-miR-101 has been proven to promote apoptosis and to suppress tumorigenicity in hepatocellular cancer (48). The tumor suppressing ability of hsa-miR-101 is further enhanced by a more recent finding that it plays a regulatory role in prostate tumorigenesis and that an increase of its levels may be a novel valuable strategy for prostate cancer treatment (49).

It is well known that hsa-miR-21 is highly expressed in the majority of human malignancies (27); however, in this study the observed difference of this oncomiR between cancer and normal tissues was not significant. This result is in agreement with other studies which found that hsa-miR-21 is not differentially expressed between cancer and normal tissues in prostate (23), gastric (26) and male breast cancer (50). On the contrary, almost all miRNA studies in head and neck cancers reported that hsa-miR-21 is up-regulated in cancers. This varied finding could be due to different approaches used for miRNA profiling as well as due to the method chosen for data analysis. Furthermore, the site of tissues chosen for expression profiling could contribute to this result. This study consists of tissues obtained from various anatomical sites in the head and neck; buccal, supraglottic, nasopharynx, retromolar, external ear and nasal cavity. The uniqueness of studied subjects is further enhanced by inclusion of three major races in Malaysia; Malay, Chinese and Indian.

The miRNA biogenesis pathway involves the stepwise processing of miRNA precursor transcripts containing hairpin structures in the nucleus as well as in the cytoplasm (51). After Drosha processing in the nucleus, miRNA containing hairpins are exported into the cytoplasm and subsequently cleaved by Dicer, resulting in the miRNA duplex (52). Both strands of miRNA duplexes are produced in equivalent amounts by transcription; however, their accumulation is mostly asymmetric at steady state. The most abundant strand of a processed 
Table IV. Summary of genes and cancer-related pathways targeted by miRNAs differentially expressed in head and neck cancers.

\begin{tabular}{|c|c|c|c|}
\hline miRNA & Summary & Putative target gene & Cancer-associated KEGG pathway \\
\hline hsa-miR-29b-1* & $\begin{array}{l}88 \text { target sites in } \\
27 \text { genes }\end{array}$ & $\begin{array}{l}\text { BHLHB3, KLF12, TSGA14, } \\
\text { CCDC117, NEUROD1 }\end{array}$ & None \\
\hline hsa-miR-181a-2* & $\begin{array}{l}58 \text { target sites in } \\
22 \text { genes }\end{array}$ & $\begin{array}{l}\text { SLC39A10, ENSG00000214728, FBN1, } \\
\text { ENSG00000183604, PLCXD1 }\end{array}$ & None \\
\hline hsa-miR-221* & $\begin{array}{l}32 \text { target sites in } \\
11 \text { genes }\end{array}$ & $\begin{array}{l}\text { ADIPOQ, ERC2, MBNL1, } \\
\text { ENSG00000127388, C16orf72 }\end{array}$ & None \\
\hline hsa-miR-1271 & $\begin{array}{l}234 \text { target sites in } \\
82 \text { genes }\end{array}$ & $\begin{array}{l}\text { ATG9A, KIAA2022, SOX5, } \\
\text { ERC2, NOVA1 }\end{array}$ & None \\
\hline hsa-miR-744 & $\begin{array}{l}61 \text { target sites in } \\
33 \text { genes; genes } \\
\text { in pathways: } 5\end{array}$ & $\begin{array}{l}\text { ILK } \\
\text { ILK } \\
\text { GNAS } \\
\text { ENSG00000100181 } \\
\text { ILK }\end{array}$ & $\begin{array}{l}\text { Endometrial cancer } \\
\text { PPAR signaling pathway } \\
\text { Gap junction } \\
\text { Wnt signaling pathway } \\
\text { Focal adhesion }\end{array}$ \\
\hline hsa-miR-181b & $\begin{array}{l}676 \text { target sites in } \\
181 \text { genes; genes } \\
\text { in pathways: } 30\end{array}$ & $\begin{array}{l}\text { SOS1, MAPK1, PAK7, RPS6KB1 } \\
\text { ACVR2A, MAPK1, ACVR2B, RPS6KB1 } \\
\text { SOS1, MAPK1, RPS6KB1 } \\
\text { NFATC2, IL1A, SOS1, MAP3K3, } \\
\text { MAPK1, RAP1B } \\
\text { NFATC2, MAPK1, NFAT5 } \\
\text { MAPK1, RPS6KB1 } \\
\text { SOS1, MAPK1, RAP1B, PAK7 } \\
\text { SOS1, MAPK1 } \\
\text { SOS1, MAPK1 } \\
\text { WASL, SOS1, MAPK1, PAK7 } \\
\text { SOS1, MAPK1 } \\
\text { NFATC2, SENP2, NFAT5 } \\
\text { LIFR, SOS1, SPRY4 } \\
\text { WASL, MAPK1 } \\
\text { LIFR, IL1A, ACVR2A, ACVR2B } \\
\text { SOS1, MAPK1 } \\
\text { SOS1, MAPK1 } \\
\text { SOS1, MAPK1 } \\
\text { SOS1, MAPK1 } \\
\text { MAPK1 } \\
\text { PRKCE } \\
\text { MAPK1 } \\
\text { MAPK1 } \\
\text { ZIC2 } \\
\text { IL1A } \\
\text { MAPK1 } \\
\text { MAPK1 }\end{array}$ & $\begin{array}{l}\text { ErbB signaling pathway } \\
\text { TGF- } \beta \text { signaling pathway } \\
\text { Acute myeloid leukemia } \\
\text { MAPK signaling pathway } \\
\text { VEGF signaling pathway } \\
\text { mTOR signaling pathway } \\
\text { Focal adhesion } \\
\text { Endometrial cancer } \\
\text { Non-small cell lung cancer } \\
\text { Regulation of actin cytoskeleton } \\
\text { Glioma } \\
\text { Wnt signaling pathway } \\
\text { Jak-STAT signaling pathway } \\
\text { Adherens junction } \\
\text { Cytokine-cytokine receptor interaction } \\
\text { Chronic myeloid leukemia } \\
\text { Colorectal cancer } \\
\text { Prostate cancer } \\
\text { Gap junction } \\
\text { Thyroid cancer } \\
\text { Tight junction } \\
\text { Bladder cancer } \\
\text { Toll-like receptor signaling pathway } \\
\text { Hedgehog signaling pathway } \\
\text { Apoptosis } \\
\text { Pancreatic cancer } \\
\text { Melanoma }\end{array}$ \\
\hline hsa-miR-181a & $\begin{array}{l}772 \text { target sites in } \\
206 \text { genes; genes } \\
\text { in pathways: } 32\end{array}$ & $\begin{array}{l}\text { SOS1, MAPK1, RAP1B, PAK7, AKT3 } \\
\text { SOS1, MAPK1, RPS6KB1, AKT3 } \\
\text { SOS1, MAPK1, PAK7, RPS6KB1, AKT3 } \\
\text { ID4, ACVR2A, MAPK1, ACVR2B, RPS6KB1 } \\
\text { PDGFRA, SOS1, MAPK1, AKT3 } \\
\text { NFATC2, PDGFRA, ATF2, SOS1, } \\
\text { MAPK1, RAP1B, NLK, AKT3 } \\
\text { WASL, MAPK1, SSX2IP, NLK } \\
\text { PDGFRA, SOS1, MAPK1, AKT3 } \\
\text { MAPK1, RPS6KB1, AKT3 } \\
\text { PDGFRA, SOS1, MAPK1, AKT3 } \\
\text { PDGFRA, SOS1, MAPK1, RAP1B, PAK7, AKT3 } \\
\text { SOS1, MAPK1, AKT3 } \\
\text { SOS1, MAPK1, AKT3 }\end{array}$ & $\begin{array}{l}\text { Renal cell carcinoma } \\
\text { Acute myeloid leukemia } \\
\text { ErbB signaling pathway } \\
\text { TGF-beta signaling pathway } \\
\text { Glioma } \\
\text { MAPK signaling pathway } \\
\text { Adherens junction } \\
\text { Colorectal cancer } \\
\text { mTOR signaling pathway } \\
\text { Prostate cancer } \\
\text { Focal adhesion } \\
\text { Endometrial cancer } \\
\text { Non-small cell lung cancer }\end{array}$ \\
\hline
\end{tabular}


Table IV. Continued.

\begin{tabular}{|c|c|c|c|}
\hline miRNA & Summary & Putative target gene & Cancer-associated KEGG pathway \\
\hline & & $\begin{array}{l}\text { NFATC2, MAPK1, AKT3 } \\
\text { PDGFRA, MAPK1, AKT3 } \\
\text { SOS1, MAPK1, AKT3 } \\
\text { PDGFRA, WASL, SOS1, MAPK1, PAK7 } \\
\text { PDGFRA, SOS1, MAPK1 } \\
\text { PRKCE, MPP5, AKT3 } \\
\text { NFATC2, NLK, SENP2 } \\
\text { SOS1, SPRY4, AKT3 } \\
\text { MAPK1, AKT3 } \\
\text { MAPK1, AKT3 } \\
\text { MAPK1 } \\
\text { MAPK1 } \\
\text { AKT3 } \\
\text { AKT3 } \\
\text { ZIC2 }\end{array}$ & $\begin{array}{l}\text { VEGF signaling pathway } \\
\text { Melanoma } \\
\text { Chronic myeloid leukemia } \\
\text { Regulation of actin cytoskeleton } \\
\text { Gap junction } \\
\text { Tight junction } \\
\text { Wnt signaling pathway } \\
\text { Jak-STAT signaling pathway } \\
\text { Pancreatic cancer } \\
\text { Toll-like receptor signaling pathway } \\
\text { Thyroid cancer } \\
\text { Bladder cancer } \\
\text { Small cell lung cancer } \\
\text { Apoptosis } \\
\text { Hedgehog signaling pathway }\end{array}$ \\
\hline hsa-miR-141 & $\begin{array}{l}306 \text { target sites } \\
\text { in } 97 \text { genes; genes } \\
\text { in pathways: } 18\end{array}$ & $\begin{array}{l}\text { E2F3, CDC14A, YWHAG } \\
\text { PRKCE, PTEN, PTENP1, MYH10 } \\
\text { E2F3, PTEN, PTENP1 } \\
\text { E2F3, PTEN, PTENP1 } \\
\text { E2F3, PTEN, PTENP1 } \\
\text { E2F3, PTEN, PTENP1 } \\
\text { E2F3 } \\
\text { PTEN, PTENP1 } \\
\text { E2F3 } \\
\text { PRKACB } \\
\text { MAP2K4, PRKACB } \\
\text { PTEN, PTENP1 } \\
\text { PTEN, PTENP1 } \\
\text { E2F3 } \\
\text { E2F3 } \\
\text { PRKACB } \\
\text { MAP2K4 } \\
\text { PRKACB } \\
\text { PRKACB } \\
\text { MAP2K4 }\end{array}$ & $\begin{array}{l}\text { Cell cycle } \\
\text { Tight junction } \\
\text { Glioma } \\
\text { Melanoma } \\
\text { Small cell lung cancer } \\
\text { Prostate cancer } \\
\text { Bladder cancer } \\
\text { Endometrial cancer } \\
\text { Non-small cell lung cancer } \\
\text { Hedgehog signaling pathway } \\
\text { MAPK signaling pathway } \\
\text { Focal adhesion } \\
\text { p53 signaling pathway } \\
\text { Pancreatic cancer } \\
\text { Chronic myeloid leukemia } \\
\text { Apoptosis } \\
\text { ErbB signaling pathway } \\
\text { Wnt signaling pathway } \\
\text { Gap junction } \\
\text { Toll-like receptor signaling pathway }\end{array}$ \\
\hline hsa-miR-95 & $\begin{array}{l}15 \text { target sites in } \\
14 \text { genes; genes } \\
\text { in pathways: } 3\end{array}$ & $\begin{array}{l}\text { GNAI2 } \\
\text { GNAI2 }\end{array}$ & $\begin{array}{l}\text { Gap junction } \\
\text { Tight junction }\end{array}$ \\
\hline hsa-miR-101 & $\begin{array}{l}335 \text { target sites in } \\
109 \text { genes; genes } \\
\text { in pathways: } 24\end{array}$ & $\begin{array}{l}\text { PTCH1, FZD4 } \\
\text { FBXW11, PTCH1 } \\
\text { MAGI2, PRKCE, MAGI1 } \\
\text { TGFBR1, FZD4 } \\
\text { TGFBR1, ACVR2B } \\
\text { TGFBR1, MAP3K4, RAP1B } \\
\text { FBXW11, FZD4 } \\
\text { SOCS5 } \\
\text { RAP1B } \\
\text { GJA1 } \\
\text { CADM1 } \\
\text { RAP1B } \\
\text { MITF } \\
\text { TGFBR1 } \\
\text { TGFBR1 } \\
\text { GJA1 } \\
\text { TGFBR1 } \\
\text { TGFBR1, ACVR2B }\end{array}$ & $\begin{array}{l}\text { Basal cell carcinoma } \\
\text { Hedgehog signaling pathway } \\
\text { Tight junction } \\
\text { Colorectal cancer } \\
\text { TGF- } \beta \text { signaling pathway } \\
\text { MAPK signaling pathway } \\
\text { Wnt signaling pathway } \\
\text { Jak-STAT signaling pathway } \\
\text { Focal adhesion } \\
\text { Cell communication } \\
\text { Cell adhesion molecules (CAMs) } \\
\text { Renal cell carcinoma } \\
\text { Melanoma } \\
\text { Adherens junction } \\
\text { Pancreatic cancer } \\
\text { Gap junction } \\
\text { Chronic myeloid leukemia } \\
\text { Cytokine-cytokine receptor interaction }\end{array}$ \\
\hline
\end{tabular}


Table V. Pathway analysis of multiple miRNAs performed with DIANA-mirPath.

Cancer-associated KEGG pathways (in up-regulated miRNAs)
Cancer-associated KEGG pathways (in down-regulated miRNAs)

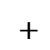

$+$

Cytokine-cytokine receptor interaction

ECM-receptor interaction

Focal adhesion

Renal cell carcinoma

Glioma

Prostate cancer

ErbB signaling pathway

Colorectal cancer

Small cell lung cancer

Endometrial cancer

TGF- $\beta$ signaling pathway

mTOR signaling pathway

MAPK signaling pathway

Non-small cell lung cancer

Melanoma

Pancreatic cancer

Acute myeloid leukemia

Chronic myeloid leukemia

Wnt signaling pathway

Adherens junction

Thyroid cancer

VEGF signaling pathway

p53 signaling pathway

Apoptosis

Jak-STAT signaling pathway

Bladder cancer

Cell communication

Cell adhesion molecules (CAMs)

Basal cell carcinoma

PPAR signaling pathway

Cell cycle

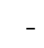

\section{$+$}

\section{$+$}

$$
+
$$$$
+
$$$$
+
$$$$
+
$$$$
+
$$$$
+
$$$$
+
$$$$
+
$$$$
+
$$$$
+
$$$$
+
$$$$
+
$$$$
+
$$$$
+
$$$$
+
$$$$
\begin{aligned}
& + \\
& +
\end{aligned}
$$$$
+
$$$$
\begin{aligned}
& + \\
& +
\end{aligned}
$$$$
\begin{aligned}
& + \\
& +
\end{aligned}
$$

$$
\begin{array}{r}
+ \\
+
\end{array}
$$$$
+
$$

$$
+
$$

$$
+
$$

$$
+
$$$$
+
$$

Only pathways mentioned in the KEGG database as being involved in human cancer are included. All of the pathways involved were found to be targeted by differentially expressed miRNAs, with the exception of the cytokine-cytokine receptor interaction pathway which was found to be influenced only by groups of up-regulated miRNAs (plus sign only for the left column of up-regulated genes).

pre-miRNA is referred as 'miRNA', whereas the less abundant strand is known as 'passenger strand' or miRNA* $(53,54)$. Three of the ten differentially expressed miRNAs in this study were miRNAs*; hsa-miR-29b-1*, hsa-miR-181a-2* and hsa-miR-221*. To date, there are no studies conducted to determine and validate the function of these miRNA*.

This research enables the identification of miRNAs that have the potential to be used as cancer markers in head and neck cancers. However, in order to identify miRNAs that could be used as markers in head and neck cancers, more miRNA expression profiling studies with a larger number of tumor samples are warranted. In addition, the differential expression of miRNAs in carcinoma samples suggests that miRNAs may be involved in cancer development (51). Furthermore, to clarify the role of individual miRNAs in head and neck cancers, the genes, functions and pathways that are regulated by the differentially expressed miRNAs should be studied. Unfortunately, due to partial complementarity of miRNAs and their target sequences, target prediction is a very challenging task and sometimes imprecise, though with the aid of special prediction algorithms. Hence, miRNA functions, target genes and regulated pathways are in need for validation before being further exploited in cancer research.

Cancer-related genes and pathways are targeted by miRNAs differentially expressed in head and neck cancers. Single and combinatorial miRNA in silico analysis revealed that miRNAs dysregulated in our study targeted genes and pathways that are involved in cancers. The data obtained from DIANAmicroT and DIANA-mirPath are summarized in Tables IV 
and $\mathrm{V}$, respectively. From the list, worth mentioning is the VEGF signaling pathway, which is influenced by all miRNAs differentially expressed in this study. The VEGF signaling pathway is well known as an important pathway in head and neck cancers and has been exploited in search for a targeted therapy of these diseases (55). Another interesting pathway regulated by our miRNAs is the p53 signaling pathway, a renowned pathway involved in tumor suppression. The p53 network suppresses tumor development through the coordinated activation of multiple transcriptional targets, and miRNAs differentially expressed in our study may act jointly with other effectors to hinder improper cell proliferation. Involvement of dysregulated miRNAs in these pathways demands future validation to prove their influence in head and neck cancers management.

In conclusion, this study is the first to describe a miRNA expression profie in Malaysian head and neck cancer patients with a focus on the identification of miRNAs differentially expressed in carcinomas vs. normal samples. Differentially expressed miRNAs in head and neck cancers vs. normal samples were identified through microarray. Up-regulation of some miRNAs from miR-181 family were observed, however, there is yet no functional study that validates its function in head and neck cancers. Three up-regulated and down-regulated miRNAs in head and neck cancers which have not been reported in other similar studies were revealed, hsa-miR-744, hsa-miR141 and hsa-miR-101. In addition, simultaneous hierarchical clustering performed on the samples was able to distinguish cancers from normal samples. In silico analysis revealed that differentially expressed miRNAs in this study are involved in cancer-related pathways. Functional analysis shall follow to validate the target and functions of these miRNAs.

\section{Acknowledgements}

The authors acknowledge the University Putra Malaysia Research University Grant Scheme (04-05-10-1109RU), the National Cancer Council Malaysia for funding and the Malaysian Cancer Statistics - Data and Figure Peninsular Malaysia 2006; the National Cancer Registry, Malaysia ISBN 978-983-343351-3; the Malaysia Genome Institute, Heliks Emas Block, UKM-MTDC Technology Centre, University Kebangsaan Malaysia.

\section{References}

1. Ragin CCR, Modugno F and Gollin SM: The epidemiology and risk factors of head and neck cancer: a focus on human papillomavirus. J Dent Res 86: 104-114, 2007.

2. Altekruse SF, Kosary CL, Krapcho M, Neyman N, Aminou R, Waldron W, Ruhl J, Howlader N, Tatalovich Z, Cho H, Mariotto A, Eisner MP, Lewis DR, Cronin K, Chen HS, Feuer EJ, Stinchcomb DG and Edwards BK (eds). SEER Cancer Statistics Review 1975-2007. National Cancer Institute. Bethesda, MD, 2010.

3. Bartel DP: MicroRNAs: target recognition and regulatory functions. Cell 136: 215-233, 2009.

4. Lee YS and Dutta A: MicroRNAs in cancer. Annu Rev Pathol 4: 199-227, 2009.

5. Lee RC,Feinbaum RL and Ambros V: The C.elegans heterochronic gene lin-4 encodes small RNAs with antisense complementarity to lin-14. Cell 75: 843-854, 1993.

6. Wightman B, Ha I and Ruvkun G: Posttranscriptional regulation of the heterochronic gene lin-14 by lin- 4 mediates temporal pattern formation in C.elegans. Cell 75: 855-862, 1993.
7. Miska EA: How microRNAs control cell division, differentiation and death. Curr Opin Genet Dev 15: 563-568, 2005.

8. Tang Y, Zheng J, Sun Y, Wu Z, Liu Z and Huang G: MicroRNA-1 regulates cardiomyocyte apoptosis by targeting Bcl-2. Int Heart J 50: 377-387, 2009.

9. Cohen EEW, Zhu H, Lingen MW, et al: A feed-forward loop involving protein kinase $\mathrm{C}$ alpha and microRNAs regulates tumor cell cycle. Cancer Res 69: 65-74, 2009.

10. Macgregor PF and Squire JA: Application of microarrays to the analysis of gene expression in cancer. Clin Chem 48: 1170-1177, 2002.

11. Gomes CC and Gomez RS: MicroRNA and oral cancer: future perspectives. Oral Oncol 44: 910-914, 2008.

12. Yan J, Burman A, Nichols C, et al: Detection of differential gene expression in brown adipose tissue of hibernating arctic ground squirrels with mouse microarrays. Physiol Genomics 25: 346-353, 2006.

13. Choi Y, Qin Y, Berger MF, Ballow DJ, Bulyk ML and Rajkovic A: Microarray analyses of newborn mouse ovaries lacking Nobox. Biol Reprod 77: 312-319, 2007.

14. Yang H, Kong W, He L, et al: MicroRNA expression profiling in human ovarian cancer: miR-214 induces cell survival and cisplatin resistance by targeting PTEN. Cancer Res 68: 425-433, 2008.

15. Xie H, Lim B and Lodish HF: MicroRNAs induced during adipogenesis that accelerate fat cell development are downregulated in obesity. Diabetes 58: 1050-1057, 2009.

16. Pandey P, Brors B, Srivastava PK, Bott A, Boehn SN, Groene HJ and Gretz N: Microarray-based approach identifies microRNAs and their target functional patterns in polycystic kidney disease. BMC Genomics 9: 624, 2008.

17. Schmittgen TD and Livak KJ: Analyzing real-time PCR data by the comparative CT method. Nat Protoc 3: 1101-1108, 2008.

18. Kanehisa M, Goto S, Furumichi M, Tanabe M and Hirakawa M: KEGG for representation and analysis of molecular networks involving diseases and drugs. Nucleic Acids Res 38: D355-D360, 2010.

19. Livak KJ and Schmittgen TD: Analysis of relative gene expression data using real-time quantitative PCR and the $2^{-\Delta \Delta C t}$. Methods 25: 402-408, 2001

20. Iorio MV, Ferracin M, Liu CG, et al: MicroRNA gene expression deregulation in human breast cancer. Cancer Res 65: 7065-7070, 2005.

21. Yanaihara N, Caplen N, Bowman E, et al: Unique microRNA molecular profiles in lung cancer diagnosis and prognosis. Cancer Cell 9: 189-198, 2006.

22. Iorio MV, Visone R, Di Leva G, et al: MicroRNA signatures in human ovarian cancer. Cancer Res 67: 8699-8707, 2007.

23. Ambs S, Prueitt RL, Yi M, et al: Genomic profiling of microRNA and messenger RNA reveals deregulated microRNA expression in prostate cancer. Cancer Res 68: 6162-6170, 2008.

24. Huang YS, Dai Y, Yu XF, Bao SY, Yin YB, Tang M and Hu CX: Microarray analysis of microRNA expression in hepatocellular carcinoma and non-tumorous tissues without viral hepatitis. J Gastroenterol Hepatol 23: 87-94, 2008.

25. Schetter AJ, Leung SY, Sohn JJ, et al: MicroRNA expression profiles associated with prognosis and therapeutic outcome in colon adenocarcinoma. JAMA 299: 425-436, 2008.

26. Luo H, Zhang Z, Zhang X, et al: MicroRNA expression signature in gastric cancer. Chin J Canc Res 21: 74-80, 2009.

27. Ramdas L, Giri U, Ashorn CL, Coombes KR, El-Naggar A, Ang KK and Story MD: miRNA expression profiles in head and neck squamous cell carcinoma and adjacent normal tissue. Head Neck 31: 642-654, 2009.

28. Lee JW, Choi CH, Choi JJ, et al: Altered microRNA expression in cervical carcinomas. Clin Cancer Res 14: 2535-2542, 2008.

29. Roehle A, Hoefig KP, Repsilber D, et al: MicroRNA signatures characterize diffuse large B-cell lymphomas and follicular lymphomas. Br J Haematol 142: 732-744, 2008.

30. Mattie MD, Benz CC, Bowers J, et al: Optimized high-throughput microRNA expression profiling provides novel biomarker assessment of clinical prostate and breast cancer biopsies. Mol Cancer 5: 24, 2006.

31. Gee HE, Camps C, Buffa FM, et al: Hsa-mir-210 is a marker of tumor hypoxia and a prognostic factor in head and neck cancer. Cancer 116: 2148-2158, 2010 .

32. Schepeler T, Reinert JT, Ostenfeld MS, et al: Diagnostic and prognostic microRNAs in stage II colon cancer. Cancer Res 68: 6416-6424, 2008.

33. Avissar M, Christensen BC, Kelsey KT and Marsit CJ: MicroRNA expression ratio is predictive of head and neck squamous cell carcinoma. Clin Cancer Res 15: 2850-2855, 2009. 
34. Cervigne NK, Reis PP, Machado J, et al: Identification of a microRNA signature associated with progression of leukoplakia to oral carcinoma. Hum Mol Genet 18: 4818-4829, 2009.

35. Karube Y, Tanaka H, Osada $\mathrm{H}$, et al: Reduced expression of Dicer associated with poor prognosis in lung cancer patients Cancer Sci 96: 111-115, 2005.

36. Thomson JM, Newman M, Parker JS, Morin-Kensicki EM, Wright $\mathrm{T}$ and Hammond SM: Extensive post-transcriptional regulation of microRNAs and its implications for cancer. Genes Dev 20: 2202-2207, 2006.

37. Lu J, Getz G, Miska EA, et al: MicroRNA expression profiles classify human cancers. Nature 435: 834-838, 2005.

38. Liang Y, Ridzon D, Wong L and Chen C: Characterization of microRNA expression profiles in normal human tissues. BMC Genomics 12: 8, 2007.

39. Rosenfeld N, Aharonov R, Meiri E, et al: MicroRNAs accurately identify cancer tissue origin. Nat Biotechnol 26: 462-469, 2008.

40. Calin GA and Croce CM: MicroRNA signatures in human cancers (Review). Nat Rev Cancer 6: 857-866, 2006.

41. Kozaki K, Imoto I, Mogi S, Omura K and Inazawa J: Exploration of tumor-suppressive microRNAs silenced by DNA hypermethylation in oral cancer. Cancer Res 68: 2094-2105, 2008.

42. Wong TS, Liu XB, Wong BY, Ng RW, Yuen AP and Wei WI: Mature miR-184 as potential oncogenic microrna of squamous cell carcinoma of tongue. Clin Cancer Res 14: 2588-2592, 2008.

43. Wang B, Hsu SH, Majumder S, Kutay H, Huang W, Jacob ST and Ghoshal K: TGF $\beta$-mediated up-regulation of hepatic miR-181b promotes hepatocarcinogenesis by targeting TIMP3. Oncogene 29: 1787-1797, 2010

44. Shi L, Cheng Z, Zhang J, Li R, Zhao P, Fu Z and You Y: hsa-mir-181a and hsa-mir-181b function as tumor suppressors in human glioma cells. Brain Res 1236: 185-193, 2008.
45. Cheng AM, Byrom MW, Shelton J and Ford LP: Antisense inhibition of human miRNAs and indications for an involvement of miRNA in cell growth and apoptosis. Nucleic Acids Res 33: 1290-1297, 2005

46. Du Y, Xu Y, Ding L, Yao H, Yu H, Zhou T and Si J: Downregulation of miR-141 in gastric cancer and its involvement in cell growth. J Gastroenterol 44: 556-561, 2009.

47. Nakada C, Matsuura K, Tsukamoto Y, et al: Genome-wide microRNA expression profiling in renal cell carcinoma: significant down-regulation of miR-141 and miR-200c. J Pathol 216: 418-427, 2008

48. Su H, Yang JR, Xu T, Huang J, Xu L, Yuan Y and Zhuang SM: MicroRNA-101, down-regulated in hepatocellular carcinoma, promotes apoptosis and suppresses tumorigenicity. Cancer Res 69: 1135-1142, 2009.

49. Cao P, Deng Z, Wan M, et al: MicroRNA-101 negatively regulates Ezh2 and its expression is modulated by androgen receptor and HIF-1alpha/HIF-1beta. Mol Cancer 9: 108, 2010.

50. Fassan M, Baffa R, Palazzo JP, et al: MicroRNA expression profiling of male breast cancer. Breast Cancer Res 11: R58, 2009.

51. Bartel DP, Lee R and Feinbaum R: MicroRNAs: genomics, biogenesis, mechanism, and function genomics: the miRNA genes. Cell 116: 281-297, 2004

52. Kim VN: MicroRNA biogenesis: coordinated cropping and dicing. Nat Rev Mol Cell Biol 6: 376-385, 2005.

53. Khvorova A, Reynolds A and Jayasena SD: Functional siRNAs and miRNAs exhibit strand bias. Cell 115: 209-216, 2003.

54. Schwarz DS, Hutvágner G, Du T, Xu Z, Aronin N and Zamore PD Asymmetry in the assembly of the RNAi enzyme complex. Cell 115: 199-208, 2003.

55. Gold KA, Lee HY and Kim ES: Targeted therapies in squamous cell carcinoma of the head and neck. Cancer 115: 922-935, 2009. 